\title{
Combination of probiotics and coccidiosis vaccine enhances protection against an Eimeria challenge
}

\author{
Miranda M. Ritzi ${ }^{1}$, Wael Abdelrahman², Kobus van-Heerden ${ }^{3}$, Michaela Mohnl' ${ }^{4}$, Nathaniel W. Barrett ${ }^{1}$ \\ and Rami A. Dalloul ${ }^{1 *}$
}

\begin{abstract}
Coccidiosis is endemic in the commercial broiler industry capable of inflicting devastating economic losses to poultry operations. Vaccines are relatively effective in controlling the disease; their efficacy could potentially be improved with concurrent use of probiotics as evaluated in this study using an Eimeria challenge. Day of hatch 400 Cobb-500 male broilers were assigned to one of four treatment groups including control (CON), vaccine-only gel application (VNC), probiotic-only gel application (NPC), and vaccine-plus-probiotic gel application (VPC). Birds were placed in floor pens ( 6 replicate pens/treatment, $16-17$ birds/pen). NPC and VPC birds received the probiotics in the water on days $2-4,8$, $14-20,22,29$, and 34-36. On day 15, birds were mildly challenged with $0.5 \mathrm{~mL}$ of a mixed oral inoculum of Eimeria sp. prepared with the coccidiosis vaccine at $10 \times$ the vaccination dose. Performance measurements were recorded on first day and weekly afterwards, and lesion scores were evaluated 6 days post-challenge. Overall, the probiotics and coccidiosis vaccine resulted in an enhanced protective effect against the challenge, with VPC birds exhibiting lower lesion scores in the duodenum than VNC or NPC birds. Birds in the VPC treatment also demonstrated higher weight gains during days $1-15$, days $7-15$, and days $21-28$ when compared to the VNC birds. These results suggest that the combination of probiotics and coccidiosis vaccines could enhance performance and provide an additional protective effect against a mixed Eimeria challenge.
\end{abstract}

\section{Introduction}

The practice of supplying food animals with sub-therapeutic doses of antibiotics to protect against coccidiosis infections and improve general intestinal health has recently been under scrutiny. The relatively recent ban of sub-therapeutic doses of certain antibiotics as feed additives in the European Union has led to a general decline in animal health with increased incidences of enteric conditions [1] known as dysbiosis. This outcome, as well as the threat of a domestic ban, has led researchers to explore the next promising alternatives including probiotics and potential combinations with live oocyst vaccines.

\footnotetext{
*Correspondence: RDalloul@vt.edu

${ }^{1}$ Avian Immunobiology Laboratory, Department of Animal \& Poultry

Sciences, Virginia Tech, Blacksburg, VA, USA

Full list of author information is available at the end of the article
}

Although the primary function of the gastrointestinal tract is to digest and absorb nutrients, a well-balanced gut microbiota is crucial for optimal animal health and performance. The gastrointestinal tract also serves as a vital barrier preventing the entry of potentially harmful pathogens and other environmental antigens [2]. As the gut microbiota begins to establish within hours after the chick hatches, the earlier the introduction of nonpathogenic microorganisms, the more effective their establishment in the digestive tract $[3,4]$. Also known as direct-fed microbials, probiotics are classified as live nonpathogenic microorganisms that are capable of maintaining a normal gut microbial population [5, 6]. Probiotics can help maintain a healthy balance of microorganisms through multiple modes of action including competitive exclusion, pathogen antagonism, and stimulation of the immune system [6, 7]. Probiotics may provide a potential alternative to the prophylactic use of drugs in food 
animals due to their studied abilities to reduce severity of enteric diseases and enhance performance in poultry [5, 8-10]. Probiotics can be composed of one or many strains of microbial species, with the more common ones belonging to the genera Lactobacillus, Bifidobacterium, Enterococcus, Bacillus, and Pediococcus [11].

Coccidiosis is endemic in the commercial broiler industry and inflicts devastating economic losses to poultry operations estimated to cost the industry about US $\$ 3$ billion annually worldwide [12]. Coccidiosis is caused by development and reproduction of multiple species of the Eimeria protozoa, leading to impaired growth and feed utilization and predisposing birds to secondary infections. Anticoccidial compounds have been used to control coccidiosis, but Eimeria species have developed resistance to both chemical and ionophore drugs over time [13]. As such, the use of live vaccines to control coccidiosis has greatly increased. Vaccines provide an alternative for disease protection, and they ultimately help in reducing Eimeria resistance as they systematically replace resistant field strains and induce specific protective immunity by exposing the chicken's immune system to Eimeria antigens [13-15]. Immunity is subsequently boosted and maintained by multiple re-infections caused by oocysts present in the litter due to shedding and ingestion [14]. Early and uniform administration of live oocysts of the vaccine results in a low level infection, necessary for immunity development. However, it can cause an early reduction in growth and may increase the chick's susceptibility to secondary infections, such as necrotic enteritis $[13,15,16]$. The potential consequences of coccidiosis vaccine administration at a young age could be overcome by proper and uniform delivery of the vaccine, as well as the chick having a healthy intestinal tract colonized by a normal pathogen-free microbiota $[13,15]$. Probiotics have the potential to enhance host defenses and affect the digestive microbiota positively, while protecting against colonization by harmful bacteria and maintaining intestinal integrity [13, 15, 17-19]. Based on these findings, probiotics may be able to attenuate the negative consequences of early vaccine administration. This study aimed to evaluate the combined protective effects of a probiotic product (PoultryStar, BIOMIN GmbH, Austria) containing Enterococcus, Bifdobacterium, Pediococcus and Lactobacillus species, and a coccidiosis vaccine (Immucox I, CEVA Santé Animale, Canada) containing Eimeria acervulina, E. maxima, E. necatrix, and E. tenella oocysts, against a coccidiosis challenge in broiler chickens.

\section{Materials and methods}

\section{Birds and experimental treatments}

The study performed was a 42-day grow-out with 400 Cobb-500 male broilers housed on randomized floor pens (furnished with $\sim 10 \mathrm{~cm}$ of clean wood shavings, which remained throughout the study period), with 6 replicate pens per treatment and 16 or 17 birds per pen. On day of hatch $(\mathrm{DOH}), 100$ birds were treated for each of the following four treatments at the hatchery: 1) control (CON), 2) vaccinated-only (VNC), 3) water-applied probiotic only (NPC), and 4) vaccinated and water-applied probiotic (VPC). VNC and VPC birds received Immucox I vaccine through gel droplet administration at the hatchery. Birds in NPC and VPC received probiotics via gel droplet application at the hatchery using a Desvac Gel Dispenser, as well as in the water intermittently through the course of the trial. The gel product was prepared using cold tap water and the dried gel component provided with the vaccine. Once water was added, the live oocyst vaccine, probiotic product, or both were added based on treatment. Then, the components were thoroughly mixed with a hand held mixer on low speed until the mixture was consistent and all probiotic product was dissolved. Once prepared, the mixture was applied using a commercial gel droplet applicator. The probiotics were administered in the water at $20 \mathrm{mg} / \mathrm{bird}$ per day on the first three days after placement, once a week, the week of Eimeria species challenge starting one day prior to inoculation, and one day before, the day of, and one day after a feed change. In summary, probiotics were administered a total of 17 time points, including days $2-4,8,14-20,22,29$, and $34-36$ (shown in Table 1). All birds received a basal diet ad libitum (Table 2). All animal protocols were approved and conducted under the guidelines of the Virginia Tech Institutional Animal Care and Use Committee.

\section{Eimeria challenge}

On day 15 of age, birds were challenged via oral gavage with $0.5 \mathrm{~mL}$ of the Immucox I coccidiosis vaccine, providing $10 \times$ the vaccine dose given at hatch, initiating a mixed Eimeria challenge. On day 21 (6 days post infection), 18 birds per treatment were randomly selected and euthanized for scoring of lesions from intestinal Eimeria infection. Lesions in the duodenum, jejunum, ileum and ceca were scored by the method of Johnson and Reid [20] by personnel blinded to treatments based on scores ranging from 0 (no gross lesion) to 4 (most severe lesion). Excreta samples were collected from each pen on days 6-8 and 14 after challenge. For each pen, fresh excreta samples were collected from either side of the feeder, either side of the water supply, and from the center of the pen. Samples were kept in separate airtight plastic bags. Starting excreta weights were recorded for each sample for later calculations of oocysts per gram of excreta as previously described [17]. After homogenization, samples were stored at $4{ }^{\circ} \mathrm{C}$ until oocysts were counted microscopically after dilution using a McMaster counting chamber and expressed as oocysts per gram of excreta. 
Table 1 Administration of probiotics (PoultryStar ${ }^{\circledR}$ ) in water to appropriate treatments

\begin{tabular}{|c|c|c|c|c|c|c|c|c|c|c|c|c|c|c|c|c|c|c|c|c|c|c|c|c|}
\hline Day & 1 & 2 & 3 & 4 & ... & 9 & $\ldots$ & 14 & 15 & 16 & 17 & 18 & 19 & 20 & $\ldots$ & 22 & $\ldots$ & 29 & $\ldots$ & 34 & 35 & 36 & $\ldots$ & 42 \\
\hline \multicolumn{25}{|c|}{ Treatment } \\
\hline \multicolumn{25}{|c|}{ CON } \\
\hline \multicolumn{25}{|c|}{ VNC } \\
\hline NPC & & * & * & * & & * & & * & * & * & * & * & $*$ & * & & * & & * & & * & * & * & & \\
\hline VPC & & * & * & * & & * & & * & $*$ & * & * & $*$ & * & * & & * & & $*$ & & * & * & * & & \\
\hline
\end{tabular}

* Indicates probiotics were included in the drinking water at $20 \mathrm{mg} / \mathrm{bird}$ in each pen.

CON: control, VNC: vaccine administration only, NPC: probiotic administration only, VPC: both vaccine and probiotic administration.

Table 2 Composition of broiler diets during 3 growing phases

\begin{tabular}{|c|c|c|c|}
\hline Item & $\begin{array}{l}\text { Starter (DOH } \\
\text { to day 15) }\end{array}$ & $\begin{array}{l}\text { Grower (days } \\
15-35)\end{array}$ & $\begin{array}{l}\text { Finisher (days } \\
\text { 35-42) }\end{array}$ \\
\hline \multicolumn{4}{|l|}{ Ingredient, \% } \\
\hline Corn & 60.55 & 65.63 & 69.90 \\
\hline Soybean meal & 22.42 & 16.43 & 10.76 \\
\hline Distiller's grain & 7.00 & 8.00 & 9.00 \\
\hline $\begin{array}{l}\text { Poultry by- } \\
\text { product meal }\end{array}$ & 5.00 & 5.00 & 4.00 \\
\hline Grease (yellow) & 1.91 & 2.12 & 2.79 \\
\hline $\begin{array}{l}\text { Dicalcium } \\
\text { phosphate }\end{array}$ & 1.15 & 0.90 & 0.78 \\
\hline L-Lysine & 0.63 & 0.60 & 0.80 \\
\hline Limestone & 0.58 & 0.54 & 0.70 \\
\hline DL-Methionine & 0.18 & 0.30 & 0.80 \\
\hline Salt & 0.27 & 0.17 & 0.16 \\
\hline L-Threonine & 0.10 & 0.10 & 0.10 \\
\hline $\begin{array}{l}\text { Southern States } \\
\text { vitamin } \\
\text { premix }\end{array}$ & 0.10 & 0.10 & 0.10 \\
\hline $\begin{array}{l}\text { Southern States } \\
\text { trace mineral } \\
\text { premix }\end{array}$ & 0.10 & 0.10 & 0.10 \\
\hline Optiphos & 0.01 & 0.01 & 0.01 \\
\hline Total & 100.00 & 100.00 & 100.00 \\
\hline \multicolumn{4}{|c|}{ Calculated nutrient level } \\
\hline $\mathrm{ME}, \mathrm{kcal} / \mathrm{kg}$ & 3036.00 & 3102.00 & 3157.00 \\
\hline$C P, \%$ & 21.00 & 19.00 & 17.00 \\
\hline $\mathrm{Ca}, \%$ & 0.90 & 0.80 & 0.76 \\
\hline Available P, \% & 0.45 & 0.40 & 0.35 \\
\hline Total P, \% & 0.71 & 0.64 & 0.57 \\
\hline $\begin{array}{l}\text { Digestible } \\
\text { Lys, \% }\end{array}$ & 1.50 & 1.33 & 1.32 \\
\hline $\begin{array}{r}\text { Digestible } \\
\text { Meth, \% }\end{array}$ & 0.50 & 0.60 & 1.06 \\
\hline $\begin{array}{l}\text { Digestible } \\
\text { Thr, \% }\end{array}$ & 0.89 & 0.81 & 0.71 \\
\hline $\begin{array}{l}\text { Digestible } \\
\text { Trp, \% }\end{array}$ & 0.22 & 0.19 & 0.16 \\
\hline
\end{tabular}

Weekly litter samples were collected from each pen to assess moisture content. Five samples were taken from each pen once a week and stored in airtight plastic bags. The samples were transferred to paper bags and placed in a drying oven at $55^{\circ} \mathrm{C}$ for $24 \mathrm{~h}$, with both starting and final weights recorded. From days 15-24, excreta in each pen were evaluated and scored for bloody diarrhea as described by Youn and Noh [21].

\section{Performance}

Pen and feed weights were taken on DOH, days 7, 15, 21, 28, 35 and 42. From these data, body weight (BW), body weight gain (BWG), feed intake (FI), and feed conversion ratio (FCR) were determined on a pen basis, and then averaged by treatment. Mortality was checked twice daily and feed consumption was corrected accordingly. One VNC pen was excluded from all calculations due to high mortality in the first week of the study due to undetermined but suspected metabolic conditions.

\section{Statistical analysis}

Data were analyzed using the Fit Model platform in JMP Pro 10.0 (SAS Institute Inc., Cary, NC, USA). For performance measurements, oocyst shedding, and litter moisture analysis, the model included treatment with pen representing the experimental unit. Lesion score analysis was performed with treatment in the model with bird serving as the experimental unit. Differences among experimental treatments were tested using Tukey HSD following ANOVA. Values were considered statistically different at $P \leq 0.05$. Results are reported as Least Square Means (LS means) with standard errors of the mean (SEM).

\section{Results \\ Eimeria challenge \\ Lesion scores}

On day 21 , a significant effect of treatment $(P<0.0001)$ was noted in lesion scores in the duodenum, the site of $E$. acervulina infection, as presented in Figure 1. The CON 


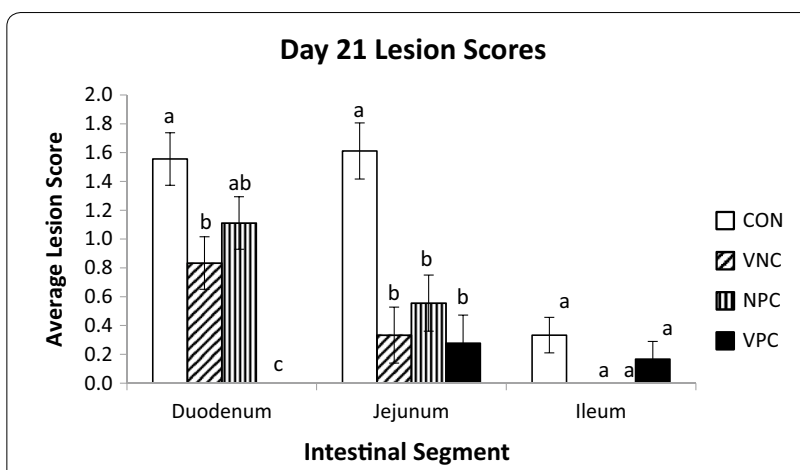

Figure 1 Effect of administration of probiotics (PoultryStar) and coccidiosis vaccine (Immucox I) on day 21 lesion scores in the duodenum, jejunum, and ileum of Cobb-500 male broiler challenged with Eimeria species on day 15. Data are presented as Least Square Mean \pm SEM; bars lacking a common letter differ significantly. CON: control; VNC: vaccine administration only; NPC: probiotic administration only, VPC: both vaccine and probiotic administration.

birds had significantly higher lesion scores than VNC and VPC birds $(P<0.0001)$. No lesions were observed in the duodenum of VPC birds, resulting in VPC being significantly different from all other treatments. The jejunum is one segment prone to damage from E. maxima and E. necatrix; the CON birds exhibited significantly higher lesions in the jejunum than all other treatments $(P<0.0001)$. No lesions were observed in the ileum of VNC or NPC birds on day 21. The average lesion scores in the ileum for CON and VPC birds were low, resulting in no significant differences seen among treatments. In addition, no lesions were observed in the ceca, the site of E. tenella infection, in any treatment (data not shown as all scores were effectively zero).

\section{Litter moisture}

Figure 2A represents the significant effect of treatment $(P=0.0119)$ on litter moisture noted on day 7 . The litter present in the VNC pens had significantly less moisture when compared to CON and VPC pens. Litter moisture also demonstrated a significant effect of treatment on day 14 (Figure 2B) where VNC pens had lower $(P<0.0001)$ litter moisture when compared to all other treatments. In addition, NPC pens had higher percent moisture of the litter when compared to the CON pens $(P<0.0001)$. At the end of the trial, a significant effect of treatment $(P=0.0245)$ was noted on percent moisture of the litter. Shown in Figure 2C, NPC pens had significantly higher percent moisture than $\mathrm{VNC}$ pens only.

\section{Bloody diarrhea scores}

No significant differences among treatments were noted regarding the presence of bloody diarrhea from days 15-24 (data not shown).

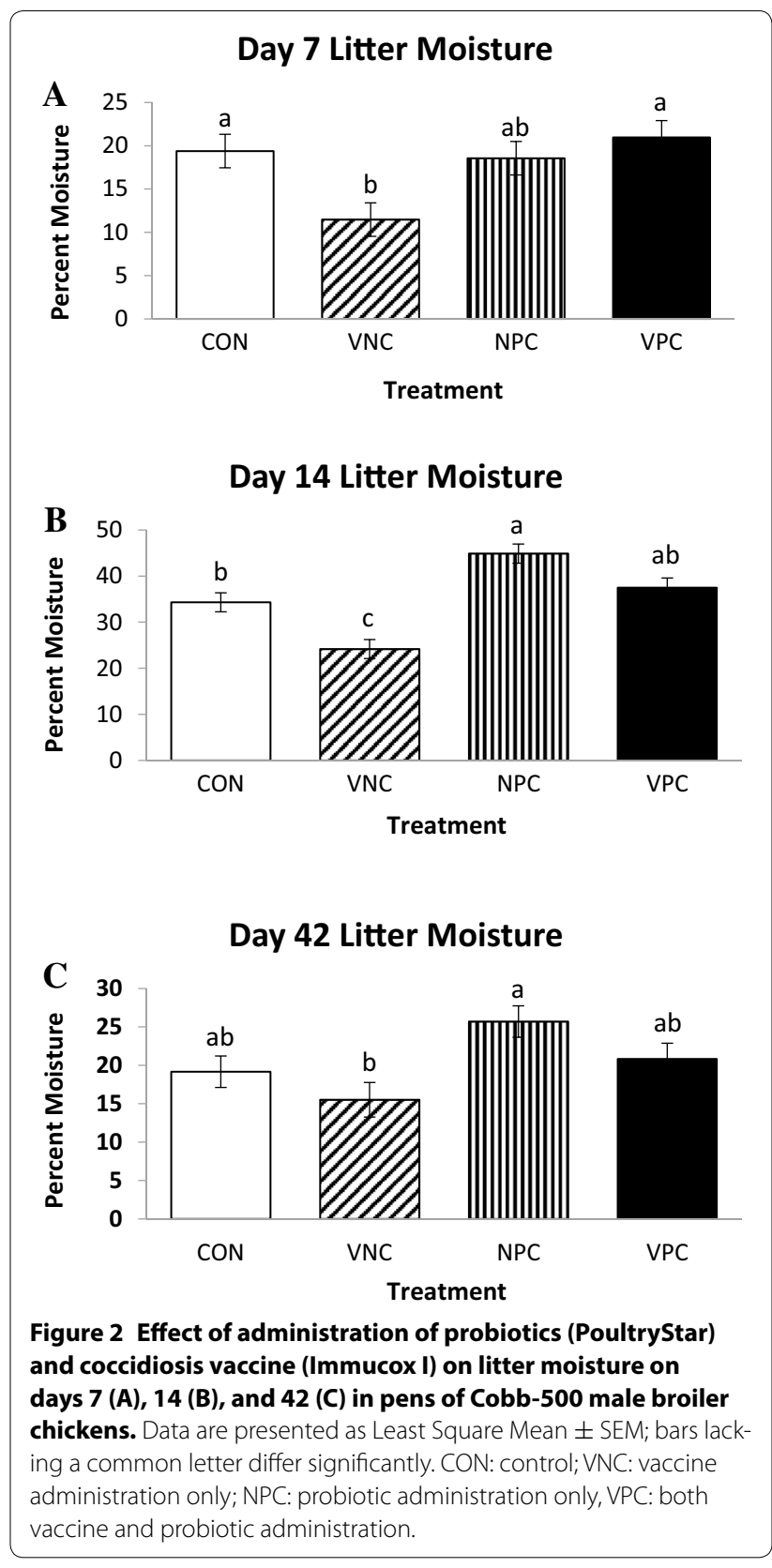

\section{Performance}

Results for performance parameters are summarized in Table 3.

\section{Body weight (BW)}

A significant effect of treatment $(P=0.00078)$ was seen on day 15, with NPC and VPC birds demonstrating significantly higher average BW than VNC birds, while CON birds were comparable to all other treatments. A significant effect of treatment was also seen on day 21, with NPC birds having greater BW than the VNC 
Table 3 Effect of administration of probiotics (PoultryStar) and coccidiosis vaccine (Immucox I) on performance

\begin{tabular}{|c|c|c|c|c|c|c|}
\hline \multirow[t]{2}{*}{ Variable } & \multicolumn{4}{|c|}{ Treatment $^{\mathrm{a}}$} & \multirow[t]{2}{*}{ SEM } & \multirow[t]{2}{*}{$P$ value } \\
\hline & CON & VNC & NPC & VPC & & \\
\hline \multicolumn{7}{|l|}{ DOH-day 7} \\
\hline DOH BW, g & $37.41^{A}$ & $37.37^{A}$ & $38.23^{A}$ & $37.39^{\mathrm{A}}$ & 0.25 & 0.6090 \\
\hline Day 7 BW, g & $150.85^{\mathrm{A}}$ & $142.37^{A}$ & $154.17^{\mathrm{A}}$ & $150.50^{\mathrm{A}}$ & 3.31 & 0.1039 \\
\hline BWG, $g$ & $113.44^{\mathrm{A}}$ & $105.00^{\mathrm{A}}$ & $116.33^{\mathrm{A}}$ & $113.1^{\mathrm{A}}$ & 3.28 & 0.1202 \\
\hline Fl, g/bird/day & $30.01^{\mathrm{A}}$ & $28.14^{\mathrm{A}}$ & $37.62^{A}$ & $37.61^{\mathrm{A}}$ & 3.31 & 0.1111 \\
\hline FCR & $1.86^{\mathrm{A}}$ & $1.85^{\mathrm{A}}$ & $2.27^{A}$ & $2.33^{\mathrm{A}}$ & 0.21 & 0.2525 \\
\hline \multicolumn{7}{|l|}{ Days 7-15 } \\
\hline Day 15 BW, g & $362.93^{\mathrm{AB}}$ & $341.23^{B}$ & $379.42^{\mathrm{A}}$ & $379.22^{\mathrm{A}}$ & 7.88 & 0.0078 \\
\hline BWG, g & $212.08^{\mathrm{AB}}$ & $198.87^{B}$ & $225.25^{\mathrm{AB}}$ & $228.72^{\mathrm{A}}$ & 7.08 & 0.0289 \\
\hline Fl, g/bird/day & $46.82^{B}$ & $59.89^{A}$ & $48.38^{\mathrm{AB}}$ & $49.03^{\mathrm{AB}}$ & 3.31 & 0.0425 \\
\hline FCR & $1.55^{\mathrm{A}}$ & $2.14^{B}$ & $1.50^{\mathrm{A}}$ & $1.51^{\mathrm{A}}$ & 0.13 & 0.0074 \\
\hline \multicolumn{7}{|l|}{ Days 15-21 } \\
\hline Day 21 BW, g & $621.35^{\mathrm{AB}}$ & $583.33^{B}$ & $709.36^{A}$ & $610.90^{A B}$ & 30.23 & 0.0434 \\
\hline BWG, g & $258.41^{\mathrm{A}}$ & $242.10^{\mathrm{A}}$ & $329.94^{\mathrm{A}}$ & $231.68^{A}$ & 28.10 & 0.0898 \\
\hline Fl, g/bird/day & $78.70^{\mathrm{A}}$ & $88.16^{\mathrm{A}}$ & $86.77^{A}$ & $82.44^{\mathrm{A}}$ & 6.08 & 0.6864 \\
\hline FCR & $1.90^{\mathrm{A}}$ & $2.02^{\mathrm{A}}$ & $1.52^{\mathrm{A}}$ & $3.34^{\mathrm{A}}$ & 0.84 & 0.4629 \\
\hline \multicolumn{7}{|l|}{ Days $21-28$} \\
\hline Day 28 BW, g & $1292.32^{\mathrm{A}}$ & $1121.92^{B}$ & $1352.72^{\mathrm{A}}$ & $1394.23^{\mathrm{A}}$ & 38.37 & 0.0008 \\
\hline BWG, $g$ & $670.97^{\mathrm{AB}}$ & $531.92^{B}$ & $643.36^{A B}$ & $783.33^{A}$ & 38.68 & 0.0032 \\
\hline $\mathrm{Fl}, \mathrm{g} / \mathrm{bird} / \mathrm{day}$ & $296.79^{A}$ & $292.01^{A}$ & $357.28^{A}$ & $351.49^{A}$ & 28.96 & 0.2824 \\
\hline FCR & $3.07^{\mathrm{A}}$ & $4.14^{\mathrm{A}}$ & $4.10^{\mathrm{A}}$ & $3.13^{\mathrm{A}}$ & 0.52 & 0.3192 \\
\hline \multicolumn{7}{|l|}{ Days 28-35 } \\
\hline Day 35 BW, g & $1935.92^{A}$ & $1847.17^{\mathrm{A}}$ & $2025.32^{A}$ & $2018.63^{A}$ & 47.01 & 0.0648 \\
\hline$B W G, g$ & $643.61^{\mathrm{A}}$ & $725.25^{\mathrm{A}}$ & $672.61^{A}$ & $624.40^{\mathrm{A}}$ & 43.82 & 0.4593 \\
\hline Fl, g/bird/day & $150.40^{\mathrm{A}}$ & $201.94^{\mathrm{A}}$ & $155.85^{A}$ & $187.38^{A}$ & 27.80 & 0.5428 \\
\hline FCR & $1.74^{\mathrm{A}}$ & $2.01^{\mathrm{A}}$ & $1.67^{\mathrm{A}}$ & $2.06^{\mathrm{A}}$ & 0.32 & 0.7782 \\
\hline \multicolumn{7}{|l|}{ Days 35-42 } \\
\hline Day 42 BW, g & $2799.75^{A}$ & $2749.44^{\mathrm{A}}$ & $2874.86^{\mathrm{A}}$ & $2835.99^{A}$ & 56.11 & 0.4954 \\
\hline$B W G, g$ & $863.83^{\mathrm{A}}$ & $902.28^{A}$ & $849.54^{\mathrm{A}}$ & $817.36^{A}$ & 47.24 & 0.6835 \\
\hline Fl, g/bird/day & $183.59^{\mathrm{A}}$ & $176.74^{\mathrm{A}}$ & $188.32^{\mathrm{A}}$ & $179.27^{\mathrm{A}}$ & 6.29 & 0.6151 \\
\hline FCR & $1.50^{\mathrm{A}}$ & $1.39^{\mathrm{A}}$ & $1.56^{\mathrm{A}}$ & $1.54^{\mathrm{A}}$ & 0.05 & 0.1237 \\
\hline \multicolumn{7}{|l|}{ DOH-day 15} \\
\hline BWG, $g$ & $325.52^{A B}$ & $303.86^{\mathrm{B}}$ & $341.58^{\mathrm{A}}$ & $341.82^{\mathrm{A}}$ & 7.84 & 0.0079 \\
\hline $\mathrm{Fl}, \mathrm{g} / \mathrm{bird} / \mathrm{day}$ & $38.62^{A}$ & $41.17^{\mathrm{A}}$ & $43.10^{\mathrm{A}}$ & $43.50^{\mathrm{A}}$ & 2.68 & 0.5680 \\
\hline FCR & $1.84^{\mathrm{B}}$ & $2.44^{\mathrm{A}}$ & $1.93^{\mathrm{AB}}$ & $1.93^{\mathrm{AB}}$ & 0.15 & 0.0358 \\
\hline \multicolumn{7}{|l|}{ Days $15-35$} \\
\hline BWG, g & $1572.99^{A}$ & $1497.69^{A}$ & $1645.91^{\mathrm{A}}$ & $1639.41^{\mathrm{A}}$ & 47.24 & 0.1589 \\
\hline $\mathrm{Fl}, \mathrm{g} / \mathrm{bird} / \mathrm{day}$ & $164.29^{A}$ & $183.29^{A}$ & $189.41^{\mathrm{A}}$ & $192.51^{\mathrm{A}}$ & 11.64 & 0.3432 \\
\hline FCR & $2.11^{\mathrm{A}}$ & $2.08^{\mathrm{A}}$ & $2.32^{\mathrm{A}}$ & $2.76^{\mathrm{A}}$ & 0.35 & 0.5153 \\
\hline \multicolumn{7}{|l|}{ DOH-day 42} \\
\hline$B W G, g$ & $2762.33^{A}$ & $2712.07^{A}$ & $2837.03^{A}$ & $2798.59^{A}$ & 56.22 & 0.4999 \\
\hline Fl, g/bird/day & $107.01^{\mathrm{A}}$ & $113.48^{\mathrm{A}}$ & $122.96^{\mathrm{A}}$ & $120.47^{\mathrm{A}}$ & 4.40 & 0.0775 \\
\hline FCR & $1.63^{\mathrm{A}}$ & $1.76^{\mathrm{A}}$ & $1.82^{\mathrm{A}}$ & $1.81^{\mathrm{A}}$ & 0.06 & 0.1383 \\
\hline
\end{tabular}

a CON: control, VNC: vaccine administration only, NPC: probiotic administration only, VPC: vaccine and probiotic administration, DOH: day of hatch.

${ }^{A-B}$ Means within rows that do not have a common superscript differ significantly $(P \leq 0.05)$. 
birds $(P=0.0434)$. However, the average body weights of CON and VPC birds did not differ significantly from each other or the other treatments on day 21. Average BW on day 28 showed a significant effect of treatment, with VNC birds weighing less than all other treatments $(P=0.0008)$.

\section{Body weight gain (BWG)}

A significant effect of treatment was seen from $\mathrm{DOH}-$ day 15 regarding BWG, with probiotic-treated birds (NPC and VPC) gaining more weight than VNC birds $(P=0.0079)$. Within the starter phase, from days $7-15$, VPC birds gained more weight than VNC birds only $(P=0.0289)$. The same trend was observed from days 21-28, where VPC birds had significantly higher BWG than VNC birds, with CON and NPC birds demonstrating comparable weight gains $(P=0.0032)$.

\section{Feed intake (FI)}

A significant effect of treatment was seen from days 7-15 regarding $\mathrm{FI}$, with $\mathrm{VNC}$ birds consuming more feed per day than CON birds $(P=0.0425)$.

\section{Feed conversion ratio (FCR)}

For the period prior to challenge (DOH-day 15), VNC birds had significantly higher FCR than CON birds $(P=0.0358)$. From days $7-15$, VNC birds demonstrated higher FCR than all other treatments $(P=0.0074)$.

\section{Discussion}

In this study, the combined protective effects of probiotics and coccidiosis vaccine in the event of an Eimeria challenge were evaluated. Birds in the combined vaccine/ probiotic treatment group had less severe duodenal lesion scores than all other treatments. Further, CON birds had lesions of greater severity than VNC birds in the duodenum, as well as lesion scores significantly greater than all other treatments in the jejunum. These findings suggest that probiotic supplementation, vaccine administration, and a combination of both help prevent damage to the intestine from coccidia. Similarly, Lee et al. [22] reported that birds given a Bacillus-based direct-fed microbial had significantly lower lesion scores in the gut than birds given the non-supplemented diet following an E. maxima challenge. Studies investigating necrotic enteritis (NE) in broilers found birds given two different blends of directfed microbials had significantly reduced intestinal lesions due to NE than birds in the positive control [23]. Additionally, birds that received just a coccidiosis vaccine had less severe lesions in the upper and middle intestinal segments following challenge with three Eimeria species when compared to non-vaccinated birds that were fed therapeutic levels of an ionophore anticoccidial [16].
A second study found that birds given one of three different coccidiosis vaccine doses had less severe lesion scores than the positive non-vaccinated control [16]. Less severe lesion scores are indicative of less damage to the intestinal epithelium, leading to infected birds having a greater chance of recovery from disease. Numerous studies have found that probiotic supplementation leads to significant reductions in numbers of other intracellular pathogens [24, 25], which could prove to be exceptionally beneficial to the bird, as some microorganisms such as Clostridium and Salmonella may exacerbate Eimeria infections and vice versa [26]. Ultimately, the reduction in the presence of intracellular pathogens is indicative of a healthier intestine, with minimal damage done to the epithelium. An intact intestinal epithelium serves as the vital barrier preventing entry of potential pathogens and results in proper nutrient absorption and utilization, leading to optimal health and performance of the bird.

The presence of oocysts in the litter and excreta after vaccination is crucial in vaccinated flocks, as it indicates proper vaccine uptake. Vaccine efficacy is dependent upon the infectivity and fecundity of oocysts, since protective immunity is induced after two to three consecutive infections $[14,27,28]$. The re-infections are initiated by recycling of initially low doses of oocysts which result in gradual buildup and maintenance of immunity, and such recycling can be impacted by a number of factors including litter moisture content $[29,30]$. The percent moisture in VNC pens was significantly lower on day 7 , day 14, and day 42 . Numerous studies have found that oocysts sporulate better in drier litter conditions, suggesting maximum sporulation rate and litter moisture are indirectly correlated $[14,26,31]$. As the infective state of the Eimeria life cycle is the sporulated oocyst, birds on litter with lower percent moisture could be introduced to a greater number of infective oocysts, leading to a heavier infection. Bloody diarrhea is commonly associated with E. tenella, which was present in the challenge inoculum. However, as no significant differences were noted, the dose of $E$. tenella present in the fresh vaccine may not have been sufficient to cause extensive damage to the site of infection, as confirmed by the absence of lesions in the ceca.

Vaccine-plus-probiotic gel application birds demonstrated significantly greater weight gains from $\mathrm{DOH}$ to day 15 when compared to VNC birds, suggesting the addition of probiotics helped the birds counter the reduction in growth associated with administration of coccidiosis live vaccines. However, the lack of a significant difference among treatments regarding $\mathrm{BW}$ at the end of the trial indicates VNC birds experienced compensatory growth following the initial setback from vaccination. These results coincide with the findings of Li et al. [16], in which 
a "reaction" caused by some doses of vaccine resulted in delayed growth and coccidial lesions during the two weeks following vaccination. However, the vaccinated birds exhibited a compensatory weight gain that brought them to weights almost equal to the unchallenged control by 5-6 weeks of age [16]. The effect of Eimeria challenge on BW and BWG is not surprising, as coccidial infections are known to cause damage to the intestinal mucosa and enterocytes during the progression of their lifecycle. Significant damage causes nutrient malabsorption and subsequent reduced performance. Furthermore, parasitic infections result in nutrient resource allocation shifting from growth to immune response, which can also lead to noticeable differences in growth $[15,29]$. Numerous studies investigating probiotics as dietary additives in poultry have resulted in varying effects of those probiotics on performance. Some reported that probiotic supplementation in the diet can improve BWG and FCR in chickens $[8,32-34]$, while others found no significant benefit to probiotic addition $[35,36]$. These differences could be due to a variety of factors that can alter the efficacy of a probiotic such as strain(s) of bacteria utilized, composition and viability of the probiotic bacteria, and the preparation methods. Further, other factors may include probiotic dosage, method and/or frequency of application, overall diet, condition and age of the birds, presence or absence of disease challenges, potential drug interactions, as well as environmental stress factors such as temperature and stocking density $[5,37]$.

Live vaccines offer a route of protection that circumvents the issue of developing drug-resistant coccidia [14, 26]. As vaccination induces protective immunity due to exposure of the immune system to Eimeria antigens, the birds may respond with a strong immune response more quickly to a field strain Eimeria infection [13, 28]. In conclusion, the administration of probiotics (PoultryStar) and coccidiosis vaccine (Immucox I) resulted in an enhanced protective effect against Eimeria acervulina and E. maxima challenge. The results of this study suggest that the combination of probiotics and coccidiosis vaccine can, when compared to untreated controls, result in better performance and intestinal response. Early establishment of beneficial microbiota by probiotics can inhibit pathogens thus potentiating a protective effect and enhancing host resistance to infection while reducing the need for prophylactic drug usage [5, 19, 38]. As PoultryStar is a product that contains multiple probiotic species of bacteria, there is a greater potential that such probiotics can be active in a wider range of conditions, similar to other multi-strain probiotics, resulting in greater efficacy $[3,39]$. Probiotics may enhance host defenses and improve vaccine response as a result of the influence of beneficial bacteria on host immunity and intestinal integrity against enteric pathogens [13, 17]. Together, probiotics and coccidiosis vaccines can benefit performance and provide an augmented protective effect in the event of an Eimeria challenge.

\section{Competing interests}

WA and MM were collaborators from Biomin that supplied the probiotic (PoultryStar ${ }^{\circledR}$ ) and KVH from CEVA that supplied the coccidiosis vaccine (Immucox $\left.1^{\circledR}\right)$.

\section{Authors' contributions}

MMR conducted the study and supervised all analyses; WA, KVH, and MM contributed to research design and manuscript revisions; NWB contributed to data acquisition throughout the course of the study; RAD was the principal investigator, involved in every aspect of this study. All authors read and approved the final manuscript.

\section{Acknowledgements}

Funding for this work was provided in part by the Virginia Agricultural Experiment Station and the Hatch Program of the National Institute of Food and Agriculture, US Department of Agriculture.

\section{Author details}

${ }^{1}$ Avian Immunobiology Laboratory, Department of Animal \& Poultry Sciences, Virginia Tech, Blacksburg, VA, USA. ${ }^{2}$ Faculty of Veterinary Medicine, Suez Canal University, Ismailia, Egypt. ${ }^{3}$ Ceva Animal Health, Guelph, Ontario, Canada.

${ }^{4}$ BIOMIN Holding GmbH, Herzogenburg, Austria.

Received: 6 August 2016 Accepted: 24 October 2016

Published online: 08 November 2016

\section{References}

1. Castanon J (2007) History of the use of antibiotic as growth promoters in European poultry feeds. Poult Sci 86:2466-2471

2. Kogut MH, Swaggerty CL (2012) Effects of prebiotics and probiotics on the host immune response. In: Callaway TR, Ricke SC (eds) Direct-Fed microbials and prebiotics for animals: science and mechanisms of action. Springer, Berlin, pp 61-72

3. Timmerman HM, Veldman A, van den Elsen E, Rombouts FM, Beynen AC (2006) Mortality and growth performance of broilers given drinking water supplemented with chicken-specific probiotics. Poult Sci 85:1383-1388

4. Torok VA, Ophel-Keller K, Hughes RJ, Forder R, Ali M, Macalpine R (2007) Environment and age: impact on poultry gut microflora. Aust Poult Sci Symp 19:149-152

5. Patterson JA, Burkholder KM (2003) Application of prebiotics and probiotics in poultry production. Poult Sci 82:627-631

6. Ohimain El, Ofongo RTS (2012) The effect of probiotic and prebiotic feed supplementation on chicken health and gut microflora: a review. Int J Anim Vet Adv 4:135-143

7. Cox CM, Dalloul RA (2015) Immunomodulatory role of probiotics in poultry and potential in ovo application. Benef Microbes 6:45-52

8. Kabir SML, Rahman MM, Rahman MB, Rahman MM, Ahmed SU (2004) The dynamics of probiotics on growth performance and immune response in broilers. Int J Poult Sci 3:361-364

9. Eckert NH, Lee JT, Hyatt D, Stevens SM, Anderson S, Anderson PN, Beltran R, Schatzmayr G, Mohnl M, Caldwell DJ (2010) Influence of probiotic administration by feed or water on growth parameters of broilers reared on medicated and non medicated diets. J Appl Poult Res 19:59-67

10. Pender CM, Kim S, Potter TD, Ritzi MM, Young M, Dalloul RA (2016) Effects of in ovo supplementation of probiotics on performance and immunocompetence of broiler chicks to an Eimeria challenge. Benef Microbes. doi:10.3920/BM2016.0080

11. Gaggia F, Mattarelli P, Biavati B (2010) Probiotics and prebiotics in animal feeding for safe food production. Int J Food Microbiol 141:S15-28

12. Dalloul RA, Lillehoj HS (2006) Poultry coccidiosis: recent advancements in control measures and vaccine development. Expert Rev Vaccines 5:143-163 
13. Stringfellow K, Caldwell D, Lee J, Mohnl M, Beltran R, Schatzmayr G, FitzCoy S, Broussard C, Farnell M (2011) Evaluation of probiotic administration on the immune response of coccidiosis-vaccinated broilers. Poult Sci 90:1652-1658

14. Williams RB (2002) Anticoccidial vaccines for broiler chickens: pathways to success. Avian Pathol 31:317-353

15. Dalloul RA, Lillehoj HS (2005) Recent advances in immunomodulation and vaccination strategies against coccidiosis. Avian Dis 49:1-8

16. Li GQ, Kanu S, Xiao SM, Xiang FY (2005) Responses of chickens vaccinated with a live attenuated multi-valent ionophore-tolerant Eimeria vaccine. Vet Parasitol 129:179-186

17. Dalloul RA, Lillehoj HS, Shellem TA, Doerr JA (2003) Enhanced mucosal immunity against Eimeria acervulina in broilers fed a Lactobacillus-based probiotic. Poult Sci 82:62-66

18. Hume ME (2011) Historic perspective: prebiotics, probiotics, and other alternatives to antibiotics. Poult Sci 90:2663-2669

19. Ritzi MM, Abdelrahman W, Mohnl M, Dalloul RA (2014) Effects of probiotics and application methods on performance and response of broiler chickens to an Eimeria challenge. Poult Sci 93:2772-2778

20. Johnson J, Reid WM (1970) Anticoccidial drugs: lesion scoring techniques in battery and floor-pen experiments with chickens. Exp Parasitol 28:30-36

21. Youn HJ, Noh JW (2001) Screening of the anticoccidial effects of herb extracts against Eimeria tenella. Vet Parasitol 96:257-263

22. Lee KW, Lillehoj HS, Jang SI, Li G, Lee SH, Lillehoj EP, Siragusa GR (2010) Effect of Bacillus-based direct fed microbials on Eimeria maxima infection in broiler chickens. Comp Immunol Microbiol Infect Dis 33:105-110

23. McReynolds J, Waneck C, Byrd J, Genovese K, Duke S, Nisbet D (2009) Efficacy of multistrain direct-fed microbial and phytogenic products in reducing necrotic enteritis in commercial broilers. Poult Sci 88:2075-2080

24. Higgins JP, Higgins SE, Vicente JL, Wolfenden AD, Tellez G, Hargis BM (2007) Temporal effects of lactic acid bacteria probiotic culture on Salmonella in neonatal broilers. Poult Sci 86:1662-1666

25. Ghareeb K, Awad WA, Mohnl M, Porta R, Biarnes M, Bohm J, Schatzmayr $G$ (2012) Evaluating the efficacy of an avian-specific probiotic to reduce the colonization of Campylobacter jejuni in broiler chickens. Poult Sci 91:1825-1832

26. Chapman HD, Cherry TE, Danforth HD, Richards G, Shirley MW, Williams RB (2002) Sustainable coccidiosis control in poultry production: the role of live vaccines. Int J Parasitol 32:617-629

27. Vermeulen AN, Schaap DC, Schetters TP (2001) Control of coccidiosis in chickens by vaccination. Vet Parasitol 100:13-20
28. Chapman HD, Roberts B, Shirley MW, Williams RB (2005) Guidelines for evaluating the efficacy and safety of live anticoccidial vaccines, and obtaining approval for their use in chickens and turkeys. Avian Pathol 34:279-290

29. Allen PC, Fetterer RH (2002) Recent advances in biology and immunobiology of Eimeria species and in diagnosis and control of infection with these coccidian parasites of poultry. Clin Microbiol Rev 15:58-65

30. Dalloul RA, Lillehoj HS, Tamim NM, Shellem TA, Doerr JA (2005) Induction of local protective immunity to Eimeria acervulina by a Lactobacillusbased probiotic. Comp Immunol Microbiol Infect Dis 28:351-361

31. Waldenstedt L, Elwinger K, Lunden A, Thebo P, Uggla A (2001) Sporulation of Eimeria maxima oocysts in litter with different moisture contents. Poult Sci 80:1412-1415

32. Apata DF (2008) Growth performance, nutrient digestibility and immune response of broiler chicks fed diets supplemented with a culture of Lactobacillus bulgaricus. J Sci Food Agri 88:1253-1258

33. Talebi A, Amirzadeh B, Mokhtari B, Gahri H (2008) Effects of a multi-strain probiotic (Primalac) on performance and antibody responses to Newcastle disease virus and infectious bursal disease virus vaccination in broiler chickens. Avian Pathol 37:509-512

34. Sen S, Ingale SL, Kim YW, Kim JS, Kim KH, Lohakare JD, Kim EK, Kim HS, Ryu MH, Kwon IK, Chae BJ (2012) Effect of supplementation of Bacillus subtilis LS 1-2 to broiler diets on growth performance, nutrient retention, caecal microbiology and small intestinal morphology. Res Vet Sci 93:264-268

35. Rahimi S, Kathariou S, Grimes JL, Siletzky RM (2011) Effect of direct-fed microbials on performance and Clostridium perfringens colonization of turkey poults. Poult Sci 90:2656-2662

36. Wolfenden RE, Pumford NR, Morgan MJ, Shivaramaiah S, Wolfenden AD, Pixley CM, Green J, Tellez G, Hargis BM (2011) Evaluation of selected direct-fed microbial candidates on live performance and Salmonella reduction in commercial turkey brooding houses. Poult Sci 90:2627-2631

37. Mountzouris KC, Tsirtsikos P, Kalamar E, Nitsch S, Schatzmayr G, Fegeros K (2007) Evaluation of the efficacy of a probiotic containing Lactobacillus, Bifidobacterium, Enterococcus, and Pediococcus strains in promoting broiler performance and modulating cecal microflora composition and metabolic activities. Poult Sci 86:309-317

38. Rolfe RD (2000) The role of probiotic cultures in the control of gastrointestinal health. J Nutr 130:396S-402S

39. Fuller R (1989) Probiotics in man and animals. J Appl Bacteriol 66:365-378

\section{Submit your next manuscript to BioMed Central and we will help you at every step:}

- We accept pre-submission inquiries

- Our selector tool helps you to find the most relevant journal

- We provide round the clock customer support

- Convenient online submission

- Thorough peer review

- Inclusion in PubMed and all major indexing services

- Maximum visibility for your research

Submit your manuscript at www.biomedcentral com/submit 